\title{
PROMOSI CARA MENCUCI TANGAN YANG BENAR DI SDN 013 TANJUNG BERULAK KECAMATAN KAMPAR KABUPATEN KAMPAR
}

\author{
Nia Aprilla ${ }^{1}$, Elvira Harmia ${ }^{2}$ \\ ${ }^{1,2)}$ Program Studi Sarjana Keperawatan, Fakultas Ilmu Kesehatan, Universitas Pahlawan Tuanku Tambusai \\ e-mail: niaaprilla.ariqa@gmail.com
}

\begin{abstract}
Abstrak
Anak-anak adalah harapan suatu bangsa. Anak-anak yang cerdas terbentuk dari anak-anak yang sehat. Masa anak-anak adalah masa yang penuh dengan aktifitas fisik. Banyaknya aktifitas yang dilakukan anak-anak membuat anak-anak banyak berhadapan dengan kotoran, keringat dan tentunya kuman. Untuk meminimalisir kuman di tubuh anak-anak tersebut, perlu diajarkan cara mencuci tangan yang benar. Anak-anak di SDN 013 Tanjung Berulak tidak tahu dan tidak paham bagaimana cara mencuci tangan yang benar. Mereka mencuci tangan hanya membasuh tangan tanpa menggosok dan tanpa menggunakan sabun. Tentu saja jika hal ini dibiarkan secara terusmenerus akan memberikan dampak negatif terhadap anak. Anak akan mudah sakit dan akhirnya sering bolos dalam sekolahnya yang menyebabkan anak tidak mengerti akan pelajaran yang dijelaskan oleh guru di sekolah. Sebaliknya jika anak mengerti dan tahu teknik mencuci tangan yang benar, maka anak-anak tidak akan mudah terserang penyakit sehingga tidak ada alasan tidak masuk sekolah. Alasan inilah yang mendorong kami untuk melakukan promosi cara mencuci tangan yang benar di SDN 013 Tanjung Berulak Kecamatan Kampar Kabupaten Kampar.
\end{abstract}

Kata kunci: Anak-Anak, Mencuci Tangan, Sehat, Sakit.

\begin{abstract}
Children are the hope of a nation. Intelligent children are made up of healthy children. Childhood is a period full of physical activity. The number of activities carried out by the children made them face a lot of dirt, sweat and of course germs. To minimize germs on the children's bodies, it is necessary to teach them how to wash their hands properly. Children at SDN 013 Tanjung Berulak do not know and do not understand how to wash their hands properly. They wash their hands, only wash their hands without rubbing and without using soap. Of course if this is allowed to continue it will have a negative impact on the children. school. Conversely, if children understand and know proper hand washing techniques, children will not be susceptible to disease so there is no reason not to go to school. It is this reason that encourages us to promote proper hand washing at SDN 013 Tanjung Berulak, Kampar District, Kampar Regency.
\end{abstract}

Keywords: Childrens, Washing Hands, Healthy, Sick.

\section{PENDAHULUAN}

Perguruan Tinggi sebagai lembaga penyelenggaraan pendidikan tinggi yang menghimpun mahasiswa sebagai peserta didik di dalamnya, memiliki tanggung jawab moral dalam menciptakan suatu kondisi yang dinamis bagi berlangsungnya suasana kondusif di kehidupan masyarakat. Perguruan tinggi sebagai tempat berlangsungnya "Learning process" berfungsi juga sebagai wahana pembentukan pribadi mahasiswa sebagai "agent of change" dan "agent of social control" di tengah-tengah masyarakat. Sehingga perguruan tinggi selayaknya tidak hanya menyelenggarakan kegiatan akademis di ruang perkuliahan semata, namun lebih dari itu, perguruan tinggi juga diharapkan mampu melahirkan insan-insan intelektual yang selain berwawasan luas dan visioner, juga memiliki kepekaan terhadap kondisi sosial masyarakat (Civil of Responsibility).

Dalam hubungannya dengan masyarakat termasuk di dalamnya adalah upaya meningkatkan derajat kesehatan kelompok anak usia sekolah melalui upaya hidup bersih dan sehat yang diselenggarakan dengan penyelenggaraan usaha kesehatan sekolah untuk meningkatkan kemampuan hidup sehat peserta didik dalam lingkungan hidup sehat sehingga peserta didik dapat 
belajar, tumbuh dan berkembang secara harmonis dan optimal sehingga diharapkan dapat menjadi sumber daya manusia yang berkualitas.

SDN 013 Tanjung Berulak adalah salah satu sekolah dasar negeri yang letaknya berada di Kecamatan Kampar dan sudah bertahun-tahun menyelenggarakan kegiatan akademis dalam membantu masyarakat menimba ilmu di sekolah tersebut. Keberadaan sekolah ini berdampak sangat positif bagi peserta didik mendapatkan pengetahuan yang baik dan berkualitas. Apalagi bila didukung oleh kegiatan ekstrakulikuler yang menambah wawasan bagi peserta didik. Kemampuan yang disalurkan bagi mereka akan berdampak terhadap perilaku hidup bersih dan sehat bagi peserta didik. Tentunya masyarakat akan merasa nyaman bila anak-anaknya selain mendapatkan pengetahuan, keterampilan juga mendapatkan nilai tambah bagi dari segi kualitas dan kuantitas.

Program Usaha Kesehatan Sekolah (UKS) merupakan tanggungjawab bersama baik dari dinas kesehatan, dinas pendidikan, departemen agama dan departemen dalam negeri sehingga dengan keterlibatan semua pihak dapat terwujud generasi penerus yang sehat secara fisik dan mental. Untuk menunjang proses pembelajaran yang kondusif, maka siswa-siswi harus mengerti dan menerapkan cara mencuci tanga yang benar dalam kehidupan sehari-hari.

\section{METODE}

Untuk mengatasi permasalah diatas, kami melakukan usaha promosi/penyuluhan cara mencuci tangan tangan yang benar di SDN 013 Tanjung Berulak Kecamatan Kampar Kabupaten Kampar. Pelaksanaan program promosi cara mencuci tangan yang benar dengan cara menjelaskan apa itu mencuci tangan, apa saja yang diperlukan dalam mencuci tangan, kapan waktu untuk mencuci tangan, manfaat mencuci tangan, dan cara mencuci tangan yang benar

\section{HASIL DAN PEMBAHASAN}

Setelah dilakukannya kegiatan, anak-anak di SDN 013 Tanjung Berulak Kecamatan Kampar Kabupaten Kampar mampu menyebutkan apa itu mencuci taga, alat-alat apa saja yang digunakan dalam mencuci tangan, serta cara mencuci tangan yang benar. Penelitian yang dilakukan oleh Purwandari, dkk (2013) dengan judul hubungan antara perilaku mencuci tangan denga insiden diare pada anak usia sekolah di Kabupaten Jember, didapatkan hasil ada hubungan yang signifikan antara mencuci tangan dengan kejadian diare.

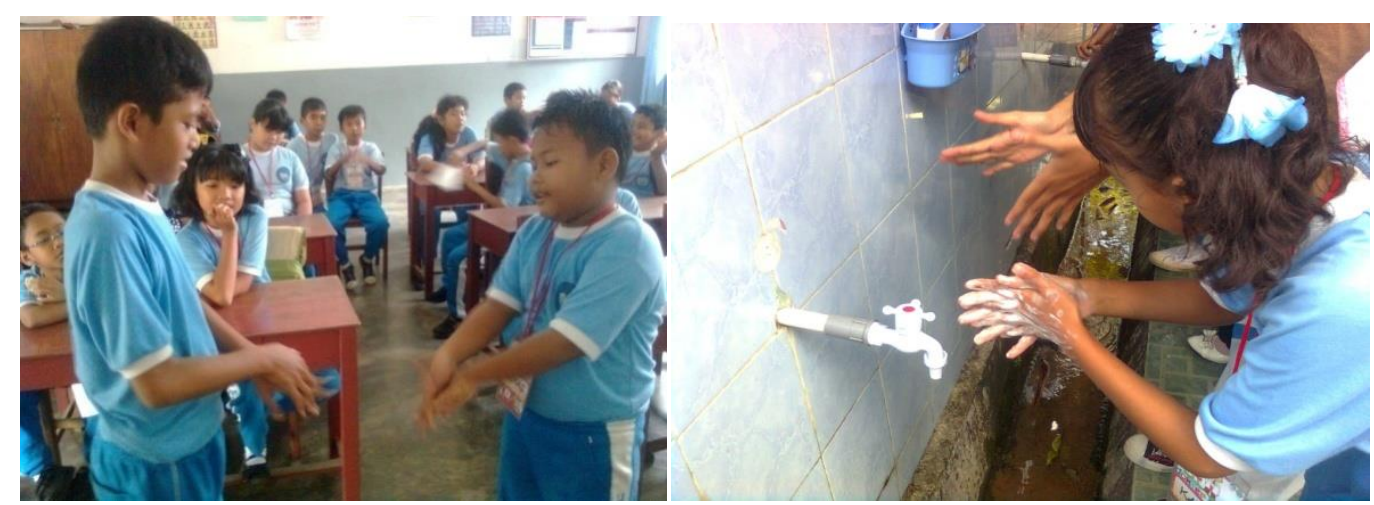

Gambar 1. Pratek mencuci tangan yang benar kepada peserta pengabdian masyarakat

\section{SIMPULAN}

Mencuci tangan merupakan salah satu cara untuk meminimalisisr perkembangan mikroorganisme di tangan kita. Karena tangan kita banyak memegang berbagai macam benda, maka harus rajin mencuci tangan. Mencuci tangan dilakukan dengan cara yang benar, memakai sabun, menggunakan 6 langkah yang benar, dan menggunakan air yang mengalir.

\section{SARAN}

Diharapkan agar bisa memberikan promosi tentang cara mencuci tangan di sekolah-sekolah dasar di Kabupaten Kampar. 


\section{UCAPAN TERIMA KASIH}

Terima kasih kami ucapkankan kepada Rektor Universitas Pahlawan Tuanku Tambusai yang telah memberikan kemudahan dalam melakukan kegiatan serta kepada pihak lembaga Universitas Pahlawan Tuanku Tambusai terkhusus kepada LPPM serta terima kasih setinggi-tingginya dihaturkan kepada Kepala Sekolah SDN 013 Tanjung Berulak yang telah memberikan izin untuk melakukan promosi/penyuluhan tentang mencuci tangan yang benar

\section{DAFTAR PUSTAKA}

Aiello. (2008). Effect of Hand Hygiene on Infectious Disease Risk in the Community Setting: A Meta-Analysis. American Journal of Public Health 2008, 98(8):1372-1381

Burton, M., Cobb, E., G,Curtis, V Donachie,P., Judah., Schmidit, W. 2011. The eff ectof handswashing with water or soap onbacterial contamination of hands. Int. J.Environ. Res. Public Health, 8, 97-104.doi:10.3390/ijerph8010097

Desiyanto., \& Djannah.2013.Efektifitas Mencuci Tangan Menggunakan Cairan Pembersih Tangan Antiseptik (HandSanitizer) Terhadap Jumlah Angka Kuman, Jurnal Kesehatan Masyarakat, Vol. 2 No.2.

Departemen Kesehatan RI. (2009). PanduanPenyelenggaraan Cuci Tangan Pakai Sabun Sedunia (HCTPS).Jakarta

Purwandari, dkk (2013). hubungan antara perilaku mencuci tangan denga insiden diare pada anak usia sekolah di Kabupaten Jember. 4(2), 122-130.

https://media.neliti.com/media/publications/138015-ID-hubungan-antara-perilaku-mencucitangan.pdf.

Undang-Undang Republik Indonesia No. 36tahun 2009 tentang Kesehatan

WHO.(2009). Guidelines on Hand Hygiene in Healthcare. Geneva: WHO.

Zuraidah, Y. 2013. Hubungan Pengetahuandan Sikap Dengan Perilaku Mencuci Tangan Dengan Benar Pada Siswa SD Kota Lubuklinggau Tahun 2013.Jurnal fakultas keperawatan. Politeknik Kesehatan Palembang 